\title{
Socio-Cultural Factors of Gender Roles in Women's Healthcare Utilization in Southwest Nigeria
}

\author{
Dominic Azuh1', Oluyemi Fayomi², Lady Ajayi² \\ ${ }^{1}$ Department of Economics and Development Studies, Covenant University, Ota, Nigeria \\ ${ }^{2}$ Political Science and International Relations, Covenant University, Ota, Nigeria \\ Email: dominic.azuh@convenantuniversity.edu.ng, nike.fayomi@covenantuniversity.edu.ng, \\ adaina.yartey@covenantuniversity.edu.ng
}

Received 15 January 2015; accepted 12 April 2015; published 15 April 2015

Copyright (C) 2015 by authors and Scientific Research Publishing Inc.

This work is licensed under the Creative Commons Attribution International License (CC BY).

http://creativecommons.org/licenses/by/4.0/

(c) (i) Open Access

\section{Abstract}

Socio-cultural factors are threat to women's health and well-being. A culture reinforces the gender role and life style of husbands and wives. No matter how equipped a health facility is, it is the patronage that makes the difference to good health. People's socio-cultural background plays vital role in seeking and acceptance of health care. The consequence of these factors on the use of health facility among pregnant women is a major cause of maternal morbidity and mortality and a powerful brake on the road to the achievement of MDGs as well as overall development. Maternal mortality in Nigeria is very high, with an estimated 52,900 Nigerian women dying from pregnancyrelated complications out of a global total of 529,000 maternal deaths. It is not encouraging to note that 62 percent of births in Nigeria occur at home and 96 percent of women who received no ANC services delivered at home. Several factors lead to health care facility utilization and among these the less studied is the socio-cultural dimension and hence the focus of the paper. The study was carried out in Ado-Odo/Ota local government area with 260 eligible respondents, selected randomly from the eight wards in the local government. Interview approach was employed with the aid of structured questionnaire to elicit required information from the respondents and data analyzed using SPSS. The main objective of this study is to understand the influence of socio-cultural factors influencing health care utilization among women during pregnancy and child birth. The findings show that husband perception of pregnancy complications, age at marriage, who pays ante-natal bills, family type, treatment place decision are significant towards use of health care services by mothers. Paper provides recommendations for improving the use of maternal health delivery services in the study area and beyond.

\section{Keywords}

Healthcare, Utilization, Culture, Gender, Maternal Health 


\section{Introduction}

Socio-cultural factors are threat to women's health and well-being, and health indicators in Nigeria are unfavorable to mothers. No matter how equipped a health facility is, it is the level of patronage that makes the difference to good health of both mother and child. People's socio-cultural background plays vital role in seeking and acceptance of health care. The consequence of these factors on the use of health facility among pregnant women is a major cause of maternal morbidity and mortality in Nigeria and a powerful brake on the road to the achievement of millennium development goals (MDGs) as well as overall development of the society. Maternal mortality in Nigeria is very high, second to India with an estimated 52,900 Nigerian women dying from pregnancy-related complications out of a global total of 529,000 maternal deaths [1]. It is not encouraging to note that 62 percent of births in Nigeria occur at home, 36 percent of women received no antenatal care, only 39 percent of births were delivered by a skilled provider and 56 percent of women did not receive any postnatal care within 41 days of delivery [2]. Several factors lead to such horrendous statistics and dismal performance on maternal health status indicators such as economic, environment, health, social and culture [3]. The last two, sociocultural factors are the less studied and hence the focus of the paper. Culture reinforces the gender roles and life style of husband and wives, making it difficult for female gender to exercise her rights including reproductive rights and behaviors. Social and cultural norms concerning gender roles powerfully shape women's autonomy [4].

Culture according to World Conference on Cultural Policies (MONDIACULT) held in Mexico City in 1982 may now be said to be the whole complex of distinctive spiritual, material and intellectual features that characterize a society or social group. It includes not only the arts and letters but, also modes of life, the fundamental rights of the human being, value systems, traditions and beliefs. It directs the roles of male and female in any society. Gender role orchestrated by cultural values, beliefs and practices promotes gender inequality and marginalization of women in a patriarchal society. No doubt pockets of matrilineal culture exist but our society is basically patrilineal in nature with little or no human rights for women. International attention given to women equality and gender studies has been soaring but it is discouraging to note that gender inequality exists even right from the family, women and employment, and women and development. It prescribes a sub-ordinate role for women leading to male dominance, low status of women and high level of dependency. Under male domination, women are usually not allowed to visit a health facility or care provider or to make the decision to spend money without the approval of the husband. As we know husband's permission and financial support are among the core aspects that affect usage of health care services. [5] opined that in many homes in South West Nigeria, husband's permission is required before a wife can seek healthcare and it depends on whether the husband sees the ill health as strong enough to warrant hospital treatment. [6] defined gender ideology based on data from a case study of a rural Ekiti Yoruba village in South Western Nigeria as beliefs about the nature of women and men and their appropriate behavior in society on reproductive decision making. Men are believed to be head of households, have authority over family members and decide on what happens in his household ranging from social, economic, cultural and health related issues. According to [7] men are believed to have superior knowledge. Adding a voice to this subject, [8] observed that many women are denied their rights and subjected to some cultural practices that greatly endanger their health in Nigeria. According to [9] women are deprived of decision making positions both in the private realm of the family and the public sector and others make decisions that directly or indirectly affect their lives on daily basis. This scenario makes it difficult for women generally to access health care even in emergency situations.

Few studies have examined explicitly the relationship between socio-cultural factors and maternal utilization of health services especially as it relates to gender roles in sub-Saharan Africa including Nigeria. For instance, [10] noted that the trend in developing countries is much worse, as studies from various countries of sub-Saharan Africa indicate that maternal mortality has not only continued to be high, but is indeed increasing after the launch of the Safe Motherhood Initiative (SMI) in Kenya in 1987. Similarly in Nigeria, not only that the Federal Ministry of Health set Year 2006 as the target year that maternal mortality would have been reduced by 50 percent but the situation of maternal health in Nigeria is now much worse than in previous years [11]. Thus, in this paper an attempt is made to examine the influence of socio-cultural factors orchestrated by gender roles on the use of maternal health care services in Ota South West Nigeria.

\section{The Objectives of This Paper Are}

1) To examine some gender related socio-cultural factors that retard maternal access to and use of health care 
services during pregnancy and childbirth.

2) To proffer informed intervention strategies for policy makers from the results of the study, for improving the current low usage of health care facilities by pregnant mothers.

\section{Research Question}

The study raises the question of how gender related socio-cultural factors retard maternal health care utilization by pregnant women.

\section{Hypothesis}

A null hypothesis was evolved to examine the influence of gender based socio-cultural factors on the use of maternal health care services among pregnant mothers in Ota South West Nigeria.

Socio-cultural engendered factors are not significant in influencing health facility utilization by pregnant women.

\section{The Theoretical Framework on Gender Roles}

Gender roles are orchestrated gender inequality. Gender roles are behavioural activities associated with sexes in a social or interpersonal relationship in a particular culture. Gender norms are reinforced in defining masculine and feminine identities. The study is based on the premise that gender roles are based on social characteristics of social roles in a society over time which is influenced by many factors. It leads to power relations between men and women and structured by culture while assigned inferior status on womenfolk. It powers access to and control over resources, decision on how to expend these resources. Under this setting women suffer from all forms of disadvantages or denials which affect their health and contribution to development processes. In order to comprehend gender roles very well, there is need to examine some theoretical framework to aid understanding of the causes of women's health care outcomes. There are several frameworks on gender roles due to the diversity of the concept but two most related to the present paper were described.

The functionalist perspective sees society as a complex system and suggests that gender inequalities exist to maximize social efficiency. This approach looks at society through a macro-level orientation and broadly focuses on the social structures that shape society as a whole. The functionalist perspective of gender inequality was most robustly articulated in the 1940s and 1950s, and largely developed by Talcott Parsons' model of the nuclear family. This theory suggests that gender inequalities exist as an efficient way to create a division of labor, or as a social system in which particular segments are clearly responsible for certain, respective acts of labor. The division of labor works to maximize resources and efficiency. A structural functionalist view of gender inequality applies the division of labor to view predefined gender role as complementary: women take care of the home while men provide for the family. Thus gender, like other social institutions contributes to the stability of society as a whole. According to [12] functionalism focuses on the structures of society and their functional significance (positive or negative consequences) for other structures. The primary concern of functionalism is the large-scale social structures and institutions of society, their interrelationships, and their constraining effects on actors. The liberal feminism theory, which is based or anchored on the ideals of equality and liberty, has bearing on gender relations. The liberal conception of equality was based on the belief that all humans had the potential to be rational and that any inequality has to be justified in rational terms. The theory argued that the reason women appear to be intellectually inferior was due to their inferior education and therefore were a result of inequality rather than a justification for it. Liberal feminists are women's subordination as resulting from general norms, rather than from biological sex and aim to change these norms. Liberal feminists focus on equal opportunity for men and women in all spheres of endeavor [13].

\subsection{Rationale of the Study}

High rates of maternal mortality and morbidity are related to knowledge about health services, the access to and utilization of services subject to availability. Examining and addressing the social-cultural dimensions of the problem is therefore as vital as dealing with the medical dimensions of maternal mortality. While existing interventions intended to benefit target group is yet to be met, the targeted Millennium Development Goal is yet to be realized. This means that there are other factors causing restraint to accessing health care service usage by 
pregnant women in addition to medical factors. No doubt some studies have been carried out in this area in Nigeria but they concentrated on intervention measures to boost maternal health services. No study has dealt exclusively at micro level on the reasons for the retardation or poor utilization of the services particularly along culturally endowed gender roles. Therefore, in order for maternal health programs to remain focused, and to make a quantitative policy impact on pregnant women, maternal mortality statistics must be available at local and national levels to prioritize the health services by decision makers in terms of intervention measures. In line with the objectives and rationale of the study, the hypothesis put forth is that socio-cultural engendered factors are not significant in influencing health facility utilization by pregnant women.

\subsection{Literature Review}

Over twenty-six years after Safe Motherhood Initiative Conference held in Nairobi, Kenya, maternal mortality has not been less instead the statistics are horrifying especially in developing countries including Africa and Nigeria. In patriarchal societies, men exercise great influence over women on all fronts including family decision making leading to incapacitating women even taking their own health decision. Reviews of related studies throw more light on the subject matter. Way back [14] refers the scenario of male dominance in family size decision as men's "situational gain” especially with respect to their children's affiliation and future support in patrilineal societies. Also [15] noted that the hierarchical nature of Yoruba society in Nigeria relegates women to a subordinate position in matters of family planning and otherwise. There is a religious dimension for the position, roles and responsibilities of husband. Biblically, the husband is the head of the households and oversees to it. According to [16] the motivation to use preventive health care requires that pregnancy and birth be conceived of as health conditions with potential risks, that problems emerging in the course of pregnancy be perceived as manageable, and that they be classified as belonging to the realm that call for action by modern health care providers. In a study among the Hausa of Northern Nigeria, [17] found that the most important factors contributing to maternal deaths are an Islamic culture that undervalues women; a perceived social need for women's reproductive capacities to be under strict male control; the practice of purdah (wife seclusion), which restricts women's access to medical care; almost universal female illiteracy; marriage at an early age and pregnancy often occurring before maternal pelvic growth is complete and harmful traditional medical beliefs and practices among others.

Education of women has a powerful role in health utilization outcomes. It acts as catalyst for changes and a transformer of high female autonomy. [14] observed that the hallmark of Kerela's success in health care use by female is better female education and autonomy. Others have equally confirmed that education of women as an important determinant of health and a valuable public good in its own right [18] [19]. Scholars like Preston, Mosley and others have suggested that culture and social systems were more important determinants of health than health systems themselves [19] [20]. Recently researchers have added to the literature on the distal determinants of health such as political, social, macroeconomic and cultural factors [21]-[23]. Similarly, [24] observed in their on dimensions of women autonomy and maternal health utilization in a North Indian city ascertain the influence of women's autonomy on the use of care during pregnancy and child birth in the study area. They further assert that the influence of women's autonomy on the use of health care appears to be as important as other known determinants such as education.

The cultural perspective on the use of maternal health services suggests that medical need is determined not only by the presence of physical disease but also by cultural perception of illness [25], influenced by individual perceptions of the efficacy of modern health services and the religious beliefs of individual women [26] and decisions about maternal care are often made by husbands or other family members [27]. It was found out that a husband's approval has a greater effect on prenatal care utilization than whether a wife wanted the pregnancy or a wife's level of education [28]. Although, women in higher socioeconomic groups tend to exhibit patterns of more frequent use of maternal health services than women in the lower socioeconomic groups, factors such as education appear to be important mediators [25] [29] [30]. Even at this, cultural tenets appear to structure women's education thereby de-accelerate female autonomy and their capacity to decide or partake in the decision making process of the family or household. In a study investigated among women from four local governments in Benue State, Nigeria [31] showed that education and domicile play significant roles in the health-seeking behavior of pregnant women.

Recently, [32] equally confirmed that women's and husband's education have a strong relationship with 
maternal health care utilization while women's autonomy had a weak relationship with various form of antenatal and delivery care usage in his study. [33] added that cultural practice of the Hausa people plays a major role in determining women's choice of place of child delivery in addition to poor hospital services and nature of attendants which may violate women's privacy. In consonance with the above finding, [34] opined that ethnicity, religion and traditional belief are often consistent as markers of cultural background and are thought to influence beliefs, norms and values in relation to child birth and service use by women. Certain ethnic or religious group may be discriminated against by staff making them less likely to use health care services. [35] argued that sociocultural beliefs and the need for immediate and specialized services have hampered women's ability to access services in many low and middle income countries including Nigeria. [36] found out that despite the fact that more than 70 percent of maternal deaths could be attributed to five major complications; poor access to and utilization of quality reproductive health services contribute significantly to the high maternal mortality level in the Nigeria.

The game of effective reduction of maternal mortality should not be left alone with the provision of facility but reengineered towards behavioral change. In a cross-sectional study in Nigeria, [37], found that efforts were required to improve men's attitudes and knowledge in order to make them appreciate and active participants in the fight to reduce maternal mortality, which begins with utilization of the available health care facility. In a hospital maternal mortality based study in Nigeria, Abe and Omo-Aghoja [38] found among leading direct and indirect causes of maternal deaths that low literacy, high poverty levels, extremes of parity and non-utilization of maternity services were associated with maternal mortality [38]. In an exploratory study which focused on socio-cultural factors affecting pregnancy outcome among the Ogu speaking people of Badagry area of Lagos State, Nigeria, [39] found that culture of the people of Ogu Community was very dominant in shaping their reproductive behavior. In a recent study among childbearing women in Ibadan North Local Government Area of Oyo State Nigeria [40] revealed that husband's decision or preference of ANC and privacy constituted the prominent factors that influenced the choice of ANC as well as place of delivery. In a study among pregnant women in Ife Central Local Government Area, Osun State, Nigeria, [41] used stratified sampling technique to select 102 pregnant women revealed among others that lack of knowledge about the existing services in ANC and Husband's acceptance of the services rendered as the major factors influencing its utilization. Using community-based research [42] found that most pregnant women had little or no contact with the health care system for reasons of custom, lack of perceived need, distance, lack of transport, lack of permission, cost and/or unwillingness to see a male doctor.

[43] found that factors like husband's approval, money for treatment, and personal cultural preferences still had negative effects on the maternal health seeking behavior in Benin Republic. A secondary data based study from the Zimbabwe Demographic and Health Survey (ZDHS) 2005-6., [44] found age, education, wealth, polygamy and religious affiliation among other variables. Commonly held beliefs and norms that could be religious or cultural, shape the way individuals perceive their own health and the health services available. Religious and cultural beliefs have been found to be sources of exclusion from maternal healthcare utilization in India and Africa [45]. Although most studies have ignored polygamy, it is a customary practice that is associated with traditionalists. [45] found that women in polygamy were less likely to report for delivery at a health institution. Maternal healthcare utilization is constrained by women's lack of decision making power, the low value placed on women's health and the negative or judgmental attitudes of family members [46]. Women with more autonomy in decision making, which is determined by the society and culture, have also been found to be more likely to use maternal healthcare [45]. Education has been found to be a source of exclusion in studies conducted in India and different countries in Africa. [47] found education linearly increasing with utilization in Ethiopia.

[48] found uneducated women less likely to use maternal healthcare, but found no differences in utilization among the educated. Education augments women's autonomy resulting in women developing greater confidence and capabilities to make decisions regarding their own health [32]. The significant impact of education on delivery at health institutions is evidence that educated women have better knowledge and information on modern medical treatment [32]. The link from education to higher utilization of health services extends to better health outcomes like lower child and maternal mortality [49]; poor use of antenatal care among Nigerian women has been a great concern to public health because of its life threatening and other negative consequences to the health of mothers and the child [50]-[52]. [53] looked into the significant determinants of antenatal care service use in Nigeria, specifically focusing on Ibadan. Four hundred women in two randomly selected local government areas of Ibadan were surveyed to achieve the study objective of investigating the factors that are associated 
with antenatal care use in Ibadan. The study revealed a significant difference in residence, religion and age in relationship with antenatal care use in Ibadan. [54] studied the factors that are significantly associated with the usage of antenatal care services in rural northern Nigeria. The study was specifically done in a village setting of Kumbotso in Kano, Nigeria. The study used data from 200 women of childbearing age in this village community to assess factors that significantly determine antenatal care use in the village. The study found that women education and the education of the husband were positively associated with antenatal care use among rural women. The higher the educational status attained the higher the use of antenatal care among women. In a community-based survey of maternal health conducted in Yirgalem town, South West Ethiopia [55] found that a husband's approval has a greater effect on prenatal care utilization than whether a wife wanted the pregnancy or a wife's level of education.

In an intra-familial power dynamics and attitudes study of 317 households in two rural districts of central Mali, [56] found that the preferences and opinions of mothers-in-law were associated with the maternal health behaviors of their daughters-in-law. In addition, they also observed that women's own perceptions of their self-efficacy, the value of women in society and the quality of services at the local health facility were independently associated with their preventive and health-seeking practices. Cultural factors have also been noted to affect the utilization of maternity care services in Africa [30]. In consonance with the above assertion, [27] corroborates that in many parts of Africa, women's decision making power is extremely limited, particularly in matters of reproduction and sexuality.

\subsection{Study Area in Context}

Ogun State is one of the six States in South-West geopolitical zone of Nigeria. It is an agricultural, industrial and educational centre located approximately between longitudes $2^{\circ} 45^{\prime} \mathrm{E}$ and $4^{\circ} 45^{\prime} \mathrm{E}$; and latitudes $6^{\circ} 15^{\prime} \mathrm{N}$ and $7^{\circ} 60^{\prime} \mathrm{N}$. The State was created out of the now defunct Western State on April 1, 1976 and has a land area of 16,762 square kilometers, representing about 1.8 percent of Nigeria's total land mass of 924,000 square kilometers. Official Statistics show that between 1991 and 2006 the population of the State grew from 2,333,726 to 3,728,098, representing about 1.7 times increase over a 15-year period (National Population Commission 2006). The 2006 National Population census figures indicate that 49.55 percent of the total population of Ogun State are female and 50.45 percent are male; suggesting that in the shortest possible time women may likely be more in number than men in this State. With an estimated population of 527,242 according to 2006 population census and land area of 1263 Square Kilometers, Ado-Odo/Ota stands out as the second largest Local Government Areas in Ogun State with a total population of 234,647 in 1991, which increased to 526,565 in 2006 The Local Government is made up of 16 political wards with only State hospital and primary health centers (PHCs).

\section{Methodology}

The study was conducted in Ado-odo/Ota Local Government Area in Ogun State Nigeria. Respondents consist of 260 women respondents who are married women in child bearing age (15 - 49) years who had at least one live birth in the last two years preceding the survey and resident in the area for at least 3 years. The sample size was made of 260 eligible women (respondents) randomly selected from 16 wards within the local government. In selecting the respondents in the absence of enumeration area demarcation map, the researchers took a census of the houses in these wards. Every 3rd house was included in the sample and one respondent was selected in each household. Where there are more than one qualified respondents in a household, the simple random sampling was used to select the respondents for interview. The research instrument used in this study was a structured questionnaire which was designed in such a way to elicit information required to achieve the goals of the study. The data obtained were analyzed with the help of SPSS.

\section{Results and Discussion}

This section discusses the results of both descriptive and regression analysis of the study. A total of 275 questionnaires were administered and 260 were retrieved corresponding to $94.5 \%$ respondents who responded with sufficient information on various aspects of the study. The descriptive results of socio-cultural characteristics of respondents have been described (see Table 1) in the appendix. It shows that an overwhelming proportion of females got married in the age group of 20 - 29 years (55.8\%) and followed by those below 19 years (17.7\%). 
Table 1. Socio-cultural characteristics of respondents.

\begin{tabular}{|c|c|c|}
\hline Variables & Number & Percent \\
\hline \multicolumn{3}{|l|}{ Age at Marriage } \\
\hline$<19$ & 46 & 17.7 \\
\hline $20-29$ & 145 & 55.8 \\
\hline $30-39$ & 45 & 17.3 \\
\hline $40+$ & 24 & 9.2 \\
\hline Total & 260 & 100.0 \\
\hline \multicolumn{3}{|l|}{ Religion } \\
\hline Christianity & 158 & 60.8 \\
\hline Islam & 76 & 29.2 \\
\hline Traditional & 26 & 10.0 \\
\hline Total & 260 & 100.0 \\
\hline \multicolumn{3}{|l|}{ Family Type } \\
\hline Extended & 88 & 33.8 \\
\hline Nuclear & 172 & 66.2 \\
\hline Total & 260 & 100.0 \\
\hline \multicolumn{3}{|l|}{ Education } \\
\hline No Education & 59 & 22.7 \\
\hline Primary & 47 & 18.2 \\
\hline Secondary & 144 & 55.5 \\
\hline Post-Secondary & 10 & 3.7 \\
\hline Total & 260 & 100.0 \\
\hline \multicolumn{3}{|l|}{ Work Status } \\
\hline Not Working & 142 & 54.6 \\
\hline Working & 118 & 45.4 \\
\hline Total & 260 & 100.0 \\
\hline
\end{tabular}

Source: Field Survey 2011.

This implies that early marriage was more prevalent in the study area. However, respondents in the age- group of 30 - 39 and 40 years and above account for $17.3 \%$ and 9.2\% respectively. Age along with sex are the basic dimensions of population composition and characteristics which are related to behavior and used to ascribe social roles though it vary over time and from one culture to another. Christian respondents constitute an overwhelming proportion, three fifths of the respondents (60.8\%), followed by Moslems (29.2\%) and traditional (10\%). Most respondents belong to nuclear family (66.2\%) than extended (33.8\%). the educational attainment of the respondents is very poor with slightly above half of the population having only secondary education (55.5\%). The respondents with no formal education and those that are have primary education accounted for 22.7 and $18.2 \%$ respectively. Nevertheless, a negligible number of the respondents had attained above secondary level education (3.6\%). This is a very serious situation in view of the importance of education as a vital force in shaping the whole gamut of an individual's life particularly mother's empowerment and accelerating women's low status. Employment status of respondents revealed those that not working, i.e. housewives and those who are not gainfully employed registered above half (54.6\%) and their counter parts in the working status only accounts for $45.4 \%$. 
On examination of gender role related health service utilization characteristics, Table 2 shows that slightly above three-fifths of the respondents (61.4\%) were satisfied by the services provided at the health facility. However, substantial proportion (38.6\%) of them registered their displeasure at the health facility services. Feeling is an internal mechanism that drives one to his or her directional behavior and when feeling is not right, the propensity to patronize will be lacking. In family decision making power including that of health and treatment place, the patriarchal domination orchestrated by gender roles manifested prominently as husband exercises an overwhelming proportion (72.7\%) or control in the affairs of his household activities. He does not only decides when and where to go, but equally who does what within the household. The implication of this is that everybody depends on one person for any move including action to seek appropriate health care. Nevertheless, the respondents account for a negligible proportion of $16.4 \%$ and spouse's relatives and friends had the least

Table 2. Health utilization characteristics of respondents.

\begin{tabular}{|c|c|c|}
\hline Variables & Number & Percent \\
\hline \multicolumn{3}{|c|}{ Perception of Health facility Services } \\
\hline Satisfactory & 160 & 61.4 \\
\hline Unsatisfactory & 100 & 38.6 \\
\hline Total & 260 & 100.0 \\
\hline \multicolumn{3}{|c|}{ Involvement in Family Decision including Treatment Place } \\
\hline Husband & 189 & 72.7 \\
\hline Wife & 43 & 16.4 \\
\hline Spouse Relatives/Friends & 28 & 10.9 \\
\hline Total & 260 & 100.0 \\
\hline \multicolumn{3}{|c|}{ Husband's Perception of dangers during pregnancy } \\
\hline Risky & 101 & 38.8 \\
\hline Non-Risky & 138 & 53.1 \\
\hline Indifference Total & $\begin{array}{c}21 \\
260\end{array}$ & $\begin{array}{c}8.1 \\
100.0\end{array}$ \\
\hline \multicolumn{3}{|l|}{ Antenatal Registration Status } \\
\hline Registered & 172 & 66.2 \\
\hline Not Registered & 88 & 33.8 \\
\hline Total & 260 & 100.0 \\
\hline \multicolumn{3}{|l|}{ ANC Payment Cost } \\
\hline Husband & 208 & 80 \\
\hline Wife & 18 & 6.9 \\
\hline Spouse Relatives/Friends & 34 & 13.1 \\
\hline Total & 260 & 100.0 \\
\hline \multicolumn{3}{|l|}{ Preferred Health Facility } \\
\hline Hospital/PHC & 117 & 45 \\
\hline Traditional Healer & 81 & 31 \\
\hline Faith Clinic & 39 & 15 \\
\hline Indifference & 23 & 9 \\
\hline Total & 260 & 100.0 \\
\hline
\end{tabular}

Source: Field Survey 2011. 
(10.9\%). A number of social and cultural practices in Nigeria limit the ability of women to take independent decisions about their own lives including the decision to seek appropriate health care. Ironically, someone who is not carrying the pregnancy is the one deciding on actions on the pregnancy, just because of gender roles and cultural ascribed functions. Husband's Perception on dangers of pregnancy complications was very low among the studied population with a high proportion of respondents' spouses not recognizing the risky nature of pregnancy (61.2\%) whereas a low proportion of them acknowledge the risky nature of the journey (38.8\%).

While registration at the health facility is encouraging with $66.2 \%$ of respondents registered at the facility, substantial proportion (33.8\%) failed to register. Needless to retort that not all those that registered will deliver in health facility due to numerous constraints such as money, permission among others. This is worrisome considering the fact that maternal morbidity and mortality in this side of the world is incomparable to most sub-Saharan African nations. The low status of women also reflected on who pays the ante natal care treatment bills. This is exclusively under the domain of the respondent's spouse (husband), especially in African countries where culturally male dominance and women subjugation are normal ways of life. In the study area, 80 percent of the respondents stated that it is their husbands who pay for the treatment costs. This is followed by spouse's relatives and friends (13.1\%) and lastly come the wife with insignificant proportion of respondents (6.9\%). This is also a restraining force to accessing health care facility. It is fascinating to note that while 45 percent of respondents in the study area preferred modern health facility, over half of the respondents (55\%) patronize non-modern facility which includes traditional healers, faith clinics and home delivery. This is a dangerous scenario considering low quality of services rendered by these untrained traditional health providers in a country beset with dismal health services.

To buttress the above findings, regression analysis was carried out (Table 3) using antenatal care registration status as a proxy dependent variable to women's health care utilization along with other independent variables such as husband's perception on dangers of pregnancy, involvement in family decision making including health and treatment place, respondent's educational attainment, age at marriage, family type, preferred health facility and antenatal care payment of treatment costs or bills. The proxy antenatal care registration status is used because it is the first step to utilization and may hence ginger full utilization during delivery. The findings show that there is significant relationship between these variables and the dependent variable, antenatal care registration status. However, husband's perception on dangers of pregnancy and respondent's involvement in family decision making including health and treatment place showed very strong relationship with the dependent variable $(\mathrm{P}=0.000)$ when compared to respondent's age at marriage, family type, and antenatal care payment of treatment costs. Nevertheless, there is no significant relationship between dependent variable and respondent's educational attainment and preferred health facility respectively. It could be that their present level of education has no transforming power in the face of strong gender roles and cultural tenacity, hence the need for higher educational attainment beyond secondary school level for more independent impact in the lives of respondents in the study area. From the ANOVA, there is also a strong relationship between these variables and the dependent variable, antenatal care registration status. Furthermore, since the F-statistics calculated (6.64) is greater than the F-tabulated (2.21), the hypothesis that gender roles do affect the utilization of health care by women is upheld in the present study. This result implies that variables relating to husband domination such as husband's perception on dangers of pregnancy, family decision making power including health and treatment place and payment of ANC treatment cost weigh more on the use of modern health care services. This could be true because in this region male dominance is culturally supported. Thus whoever is in charge of both fund and decision/or power is in control and subsequently decides where the dice is cast.

\section{Policy Implications and Recommendations}

Maternal health utilization research is essential in actualizing MDGs of reducing maternal mortality in less than 1000 days. Hence, the following recommendations may go a long way in the quest for a lasting solution in the campaign to stem maternal mortality and accelerate the utilization of health facilities in the study area, Nigeria and other regions:

1) Costs alleviation for women seeking antenatal care and delivery services should be put in place to encourage women to patronize health services.

2) Restoration of the dignity of women, through education and empowerment for the prospective mothers. Education will transform women, enhance their present low status and bring women on board the decision- 
Table 3. Regression analysis results of the effects of selected independent variables on the respondent's antenatal care registration status.

\begin{tabular}{ccccc}
\hline & \multicolumn{2}{c}{ Model Summary $^{\mathbf{b}}$} \\
\hline Model & $\mathrm{R}$ & R Square & Adjusted R Square & Std. Error of the Estimate \\
\hline 1 & $0.375^{\mathrm{a}}$ & 0.141 & 0.119 & 0.772 \\
\hline
\end{tabular}

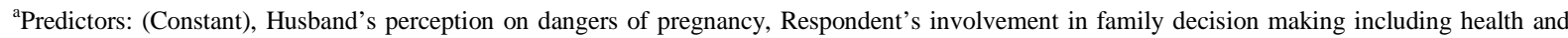
treatment place, Respondent's educational attainment, Respondent's age at marriage, Family type, Preferred health facility, Antenatal care payment of treatment costs. ${ }^{b}$ Dependent Variable: Antenatal care registration status.

\begin{tabular}{|c|c|c|c|c|c|c|}
\hline \multicolumn{7}{|c|}{ ANOVA $^{b}$} \\
\hline & Model & Sum of Squares & $\mathrm{df}$ & Mean Square & $\mathrm{F}$ & Sig. \\
\hline \multirow{3}{*}{1} & Regression & 27.689 & 7 & 3.956 & 6.638 & $0.000^{\mathrm{a}}$ \\
\hline & Residual & 169.229 & 241 & 0.596 & & \\
\hline & Total & 196.918 & 248 & & & \\
\hline
\end{tabular}

${ }^{\text {a } P r e d i c t o r s: ~(C o n s t a n t), ~ H u s b a n d ' s ~ p e r c e p t i o n ~ o n ~ d a n g e r s ~ o f ~ p r e g n a n c y, ~ R e s p o n d e n t ' s ~ i n v o l v e m e n t ~ i n ~ f a m i l y ~ d e c i s i o n ~ m a k i n g ~ i n c l u d i n g ~ h e a l t h ~ a n d ~}$ treatment place, Respondent's educational attainment, Respondent's age at marriage, Family type, Preferred health facility, Antenatal care payment of treatment costs. ${ }^{\mathrm{b}}$ Dependent Variable: Antenatal care registration status.

\begin{tabular}{|c|c|c|c|c|c|c|}
\hline \multicolumn{7}{|c|}{ Coefficients $^{\mathrm{a}}$} \\
\hline & \multirow{2}{*}{ Model } & \multicolumn{2}{|c|}{ Unstandardized Coefficients } & \multirow{2}{*}{$\begin{array}{c}\text { Standardized } \\
\text { Coefficients } \\
\text { Beta }\end{array}$} & \multirow{2}{*}{$\mathrm{t}$} & \multirow{2}{*}{ Sig. } \\
\hline & & B & Std0. Error & & & \\
\hline \multirow{8}{*}{1} & (Constant) & 0.370 & 0.360 & & 1.028 & 0.305 \\
\hline & $\begin{array}{l}\text { Husband's perception on dangers of } \\
\text { pregnancy }\end{array}$ & 10.317 & 0.298 & 0.245 & 4.416 & 0.000 \\
\hline & $\begin{array}{l}\text { Respondent's involvement in family } \\
\text { decision making including health and } \\
\text { treatment place }\end{array}$ & 0.173 & 0.042 & 0.257 & 0.323 & 0.000 \\
\hline & Respondent's educational attainment & 0.050 & 0.055 & 0.051 & 0.916 & 0.361 \\
\hline & Respondent's age at marriage & -0.120 & 0.044 & -0.156 & -2.759 & 0.006 \\
\hline & Family type & 0.062 & 0.022 & 0.159 & 2.817 & 0.005 \\
\hline & Preferred health facility & 0.002 & 0.002 & 0.058 & 1.030 & 0.304 \\
\hline & $\begin{array}{l}\text { Antenatal care payment of treatment } \\
\text { costs }\end{array}$ & 0.171 & 0.056 & 0.171 & 3.020 & 0.003 \\
\hline
\end{tabular}

${ }^{\mathrm{a}}$ Dependent Variable: Antenatal care registration status.

making realm including health care. In addition, education may increase and usher in late marriage which will reduce early pregnancy among women in the study area.

3) Specially designed education including health and population education should be given to men in order to increase their perception about pregnancy and make them to be more responsible in taking total care of their wives.

4) Ratification and Domestication of the Protocol on Women's Rights in Africa and CEDAW is the first steps to guaranteeing the rights of women at state and national levels in Nigeria. The provisions of Article 14 (Health and Reproductive Rights), and Article 15 (Right to Food Security) of the Protocol on Women's Rights in Africa provide some bench marks that Nigeria can aspire to attain once the Protocol is domesticated in Nigeria. Nigerian was among the first to sign to these documents but further action especially on the CEDAW to enable legislation has been delayed to the great disadvantage of attaining the health of women [55].

\section{Conclusion}

Maternal mortality in developing countries continues to be a serious public health problem and contributes to the 
low life expectancy in Nigeria. The study has identified several factors that have important influence on utilization of maternal health services in the study area. Among these include the husband's perception on dangers of pregnancy, respondent's involvement in family decision making including health and treatment place, respondent's age at marriage, family type and antenatal care payment of treatment costs. The study equally recommends culturally appropriate health education especially on harmful traditional practices and benefits of safe motherhood should be employed as a short-term measure. Socio-economic transformation and "cultural revolution" should be effected for better healthcare utilization among pregnant women. However, a more nationally representative survey study including urban and rural areas is needed to help examine extensively the sociocultural factors limiting maternal utilization of health services in Nigeria for wider application of findings.

\section{References}

[1] Federal Ministry of Health (2007) Nature, Strategic Framework on the Health and Development of Adolescents and Young people in Nigeria. Federal Ministry of Health, Abuja.

[2] Nigeria Demographic and Health Survey (NDHS) (2000) Nigeria: DHS, 1999_Final Report. Measure DHS, Calverton.

[3] Jenna, K, Muller, B. and Quiros, A. (2009) Women, Men, and the Changing Role of Gender in Immigration. Student Research Series, 3, 1-14.

[4] Jejeebhoy, S.J. (2002) Convergence and Divergence in Spouses’ Perspectives on Women’s Autonomy in Rural India. Studies in Family Planning, 33, 299-308. http://dx.doi.org/10.1111/j.1728-4465.2002.00299.x

[5] Jejeebhoy, S.J. (2001) Women's Autonomy in India and Pakistan: The Influence of Religion and Region. Population and Development Review, 27, 687-712. http://dx.doi.org/10.1111/j.1728-4457.2001.00687.x

[6] Adewuyi, A. (1999) Understanding Male Involvement in Maternal Emergencies. Oke Gada, Ede.

[7] Renne, E.P. (1993) Gender Ideology and Fertility Strategies in an Ekiti Yoruba Village. Studies in Family Planning, 24, 343-353. http://dx.doi.org/10.2307/2939244

[8] Omideyi, A. (1987) Status, Cultural Beliefs and Fertility Behavior among Yoruba Women. In: Ebigbola, J. and Van de Walle, E., Eds., The Cultural Roots of African Fertility Regimes: Proceedings of the Ife Conferences, Obafemi Awolowo University, Ile-Ife and University of Pennsylavania, Philadelphia, 151-165.

[9] Mama, A. (1996) Women's Studies and Studies of Women in Africa during the 1990s. Working Paper Series 5/96, CODESRIA, Daker.

[10] Longwe, S.H. (2002) Assessment of the Gender Orientation of NEPAD. In: Nyong’o, P.A., Ed., New Partnership for Africa's Development NEPAD: A New Path, Heinrich Boll Foundation, Nairobi, 252-274.

[11] Shah, I.H. and Say, L. (2007) Maternal Mortality and Maternity Care from 1990-2005: Uneven but Important Gains. Reproductive Health Matters, 15, 17-27. http://dx.doi.org/10.1016/S0968-8080(07)30339-X

[12] Ujah, I.A.O., Aisien, O.A., Mutihir, J.T., Vanderagt, D.J., Glew, R.H. and Uguru, V.E. (2005) Factors Contributing to Maternal Mortality in North-Central Nigeria: A Seventeen-Year Review. African Journal of Reproductive Health, 9, 27-40. http://dx.doi.org/10.2307/3583409

[13] Dyson, T. and Moore, M. (1993) On Kinship Structure, Female Autonomy and Demographic Behaviour in India. Population and Development Review, 9, 35-60. http://dx.doi.org/10.2307/1972894

[14] Parpart, J., Connelly, M. and Barriteu, V. (2000) Theoretical Perspectives on Gender and Development. International Development Research Centre, Ottawa.

[15] Caldwell, J.C. (1986) Routes to Low Mortality in Poor Countries. Population and Development Review, 12, $171-220$. http://dx.doi.org/10.2307/1973108

[16] Caldwell, J.C. (1977) Towards a Restatement of Demographic Transition Theory. In: John, C.C., Ed., The Persistence of High Fertility, Australian National University, Canberra, 25-119.

[17] Afonja, S. (1986) Women Power and Authority in Traditional Yoruba Society. In: Dube, L., Leacock, E. and Ardener, S., Eds., Visibility and Power, Bergin and Garvey, South Hadley, 136-157.

[18] Obermeyer, C.M. (1993) Culture, Maternal Health Care, and Women’s Status: A Comparison of Morocco and Tunisia. Studies in Family Planning, 24, 354-365. http://dx.doi.org/10.2307/2939245

[19] Wall, L.L. (1998) Dead Mothers and Injured Wives: The Social Context of Maternal Morbidity and Mortality among the Hausa of Northern Nigeria. Studies in Family Planning, 29, 341-359. http://dx.doi.org/10.2307/172248

[20] Soares, R.R. (2005) Mortality Reductions, Educational Attainment, and Fertility Choice. American Economic Review, 95, 580-601. http://dx.doi.org/10.1257/0002828054201486 
[21] Mosley, W.H. and Lincoln, C.C. (1984) An Analytical Framework for the Study of Child Survival in Developing Countries. Population and Development Review, 10, 25-45. http://dx.doi.org/10.2307/2807954

[22] Mosley, W.H. (1984) Child Survival: Research and Policy. Population and Development Review, 10, 3-23. http://dx.doi.org/10.2307/2807953

[23] Preston, S.H. and Haines, M.R. (1991) Fatal Years: Child Mortality in Late Nineteenth Century America. Princeton University Press, Princeton. http://dx.doi.org/10.1515/9781400861897

[24] Subramanian, S.V., Belli, P. and Kawachi, I. (2002) The Macroeconomic Determinants of Health. Annual Review of Public Health, 23, 287-302. http://dx.doi.org/10.1146/annurev.publhealth.23.100901.140540

[25] Marmot, M. (2005) Social Determinants of Health Inequalities. The Lancet, 365, 1099-1104. http://dx.doi.org/10.1016/S0140-6736(05)74234-3

[26] Lieberman, E.S. (2007) Ethnic Politics, Risk, and Policy-Making: A Cross-National Statistical Analysis of Government Responses to HIV/AIDS. Comparative Political Studies, 40, 1407-1432. http://dx.doi.org/10.1177/0010414007306862

[27] Bloom, S.S., Wypij, D. and Das Gupta, M. (2001) Dimensions of Women’s Autonomy and the Influence on Maternal Health Care Utilization in a North Indian City. Demography, 38, 67-78. http://dx.doi.org/10.1353/dem.2001.0001

[28] Addai, I. (2000) Determinants of Use of Maternal Child Health Services in Rural Ghana. Journal of Biosocial Science, 32, 1-15.

[29] Adetunji, J.A. (1991) Response of Parents to Five Killer Diseases among Children in a Yoruba Community, Nigeria. Social Science and Medicine, 32, 1379-1387. http://dx.doi.org/10.1016/0277-9536(91)90198-L

[30] World Health Organization (1998) Improved Access to Maternal Health Service. World Health Organization, Geneva.

[31] Biratu, B.T. and Lindstrom, D.P. (2006) The Influence of Husbands’ Approval on Women’s Use of Prenatal Care: Results from Yirgalem and Jimma Towns, South West Ethiopia. Ethiopian Journal of Health Development, 20, 84-92.

[32] Addai, I. (1998) Demographic and Socio-Cultural Factors Influencing Use of Maternal Health Services in Ghana. African Journal of Reproductive Health, 2, 73-80.

[33] Leslie, J. and Gupta, G.R. (1989) Utilization of Formal Services for Maternal Nutrition and Health Care. International Center for Research on Women, Washington DC.

[34] Kistiana, S. (2009) Socio-Economic and Demographic Determinants of Maternal Health Care Utilization in Indonesia. Unpublished Master's Theses, The Flinders University of South Australia, Adelaide.

[35] Okeshola, F.B. and Ismail, T.S. (2013) Determinants of Home Delivery among Hausa in Kaduna South Local Government Area of Kaduna State, Nigeria. American International Journal of Contemporary Research, 3, 78.

[36] Elo, I.T. (1992) Utilization of Maternal Health Care Services in Peru: The Role of Women's Education. Health Transition Review, 2, 49-69.

[37] Gabrysch, S. and Campbell, O.M.R. (2009) Still Too Far to Walk: Literature Review of the Determinants of Delivery Service Use. BMC Pregnancy and Childbirth, 9, 34. http://dx.doi.org/10.1186/1471-2393-9-34

[38] Omoruyi, G. (2008) Causes of Maternal Mortality in Nigeria. Sunday Observer.

[39] Lawoyin, T.O., Lawoyin, O.O.C. and Adewole, D.A. (2007) Men’s Perception of Maternal Mortality in Nigeria. Journal of Public Health Policy, 28, 299-318. http://dx.doi.org/10.1057/palgrave.jphp.3200143

[40] Ajiboye, O.E. and Adebayo, K.A. (2012) Socio-Cultural Factors Affecting Pregnancy Outcome among the Ogu Speaking People of Badagry Area of Lagos State, Nigeria. International Journal of Humanities \& Social Science, 2, 133.

[41] Ewa, E.E., Lasisi, C.J., Maduka, S.O., Ita, A.E., Ibor, U.W. and Anjorin, O.A. (2012) Perceived Factors Influencing the Choice of Antenatal Care and Delivery Centres among Childbearing Women in Ibadan North South-Western, Nigeria. Ethiopian Journal of Environmental Studies and Management, 5, 373-383. http://dx.doi.org/10.4314/ejesm.v5i4.6

[42] Onasoga, O.A., Afolayan, J.A. and Oladimeij, B.D. (2012) Factors Influencing Utilization of Antenatal Care Services among Pregnant Women in Ife Central Lga, Osun State, Nigeria. Advances in Applied Science Research, 3, 1309-1315.

[43] Owumi, B. and Raji, S.O. (2013) Socio-Cultural Determinants of Maternal Health Care Seeking Behavior in Seme Side of Benin Republic. African Journal of Social Sciences, 3, 145-158.

[44] Muchabaiwa, L., Mazambani, D., Chigusiwa, L., Bindu, S. and Mudavanhu, V. (2012) Determinants of Maternal Healthcare Utilization in Zimbabwe. International Journal of Economic Sciences and Applied Research, 5, 145-162.

[45] Stephenson, R., Baschieri, A., Clements, S., Hennink, M. and Madise, N. (2006) Contextual Influences on the Use of Health Facilities for Childbirth in Africa. American Journal of Public Health, 96, 84-93. http://dx.doi.org/10.2105/AJPH.2004.057422

[46] World Health Organization (2005) The World Health Report 2005. World Health Organization, Geneva. 
[47] Mekonnen, Y. and Mekonnen, A. (2002) Utilization of Maternal Health Care Services in Ethiopia. ORC Marco, Maryland.

[48] Navaneetham, K. and Dharmalingam, A. (2000) Utilization of Maternal Healthcare Services in South India. Faculty Seminar at the Centre for Development Studies, Thiruvananthapuram, 31 March 2000, 1-40.

[49] Boyle, M.H., Racine, Y., Georgiades, K., Snelling, D., Hong, S., Omariba, W., Hurley, P. and Rao-Melacini, P. (2006) The Influence of Economic Development Level, Household Wealth and Maternal Education on Child Health in the Developing World. Social Science and Medicine, 63, 2242-2254. http://dx.doi.org/10.1016/j.socscimed.2006.04.034

[50] McCarthy, J. and Maine, D. (1992) A Framework for Analyzing the Determinants of Maternal Mortality. Studies in Family Planning, 23, 23-33. http://dx.doi.org/10.2307/1966825

[51] Dairo, M.D. and Owoyokun, K.E. (2010) Factors Affecting the Utilization of Antenatal Care Services in Ibadan, Nigeria. Benin Journal of Postgraduate Medicine, 12, 3-13.

[52] Kabir, M., Iluyasu, Z., Abubakar, I.S. and Sani, A.A. (2005) Determinants of Utilization of Antenatal Care Services in Kumbotso Village, Northern Nigeria. Tropical Doctor, 35, 110-111. http://dx.doi.org/10.1258/0049475054036814

[53] Biratu, B.T. and Lindstrom, D.P. (2000) The Influence of Husbands’ Approval on Women’s Use of Prenatal Care: Results from Yirgalem and Jimma Towns, South West Ethiopia. Ethiopian Journal of Health Development, 20, 84-92.

[54] White, D., Dynes, M., Rubardt, M., Sissoko, K. and Stephenson, R. (2013) The Influence of Intra-Familial Power on Maternal Health Care in Mali: Perspectives of Women, Men and Mothers-in-Law. International Perspectives on Sexual and Reproductive Health, 39, 58-68.

[55] Fayomi, O.O. and Igbokwe, N. (2009) Women's Reproductive Health-A Question of Human Rights in the context of HIV/AIDS in Nigeria. MP: A Feminist Journal (Gender and Race), 2, 30.

[56] Azuh, D. (n.d.) Socio-Demographic Factors Influencing Health Programme Usage by Pregnant Mothers in Nigeria: Implications for Policy Action. Unpublished Work, Covenant University, Ota. 